\title{
An exploration investigation on important factors influencing pricing strategy for market share adjustment
}

\author{
Somayeh Hozouri", Gholamreza Heidari Kord Zangeneh and Naser Azad
}

Department of Management, Islamic Azad University, South Tehran Branch, Tehran, Iran

\section{H R O N I C L E}

Article history:

Received June 10, 2013

Received in revised format

25 August 2013

Accepted September 262013

Available online

October 152013

Keywords:

Pricing

Factor analysis

Market share

\section{A B S T R A C T}

\begin{abstract}
During the past few years, there have been growing competition among business owners and they mostly have no choice but to decrease their prices in an attempt to survive on the market. In some cases, suppliers offer goods and services for less than the cost of production to gain more market share. In this paper, we study different factors influencing pricing strategy in food industry. The proposed study designs a questionnaire in Likert scale consists of 36 questions, distributes it among 311 Iranian experts in food industry and analyzes it based on principal component analysis. Cronbach alpha is calculated as 0.86 and Kaiser-Meyer-Olkin Measure of Sampling Adequacy and Approx. Chi-Square are 0.72 and 3614, respectively. Based on the results of our survey, we have derived seven factors including supply management, environmental factors, product management, distribution structure, standardization strategies, market leadership and market organization.
\end{abstract}

(C) 2014 Growing Science Ltd. All rights reserved.

\section{Introduction}

During the past few years, there has been growing interest on choosing the best pricing and marketing strategies (Azad \& Hassanabadi, 2013a, 2013b). We have seen a growing increase on competition among business owners and they need to have competitive pricing strategies. Some choose penetrating strategies; the others try to use dumping strategies trying to gain more market share (Mainela \& Ulkuniemi, 2012). There are literally various studies on detecting important factors influencing marketing planning and most of these techniques use multiple criteria decision making to handle various factors, which are mostly in conflict. In fact, when a person purchases products, he/she may consider the brand first since it associates the products with the quality, functions, and the design. Wang and Tzeng (2012) evaluated the customer's satisfaction of brand marketing by three electronic manufacturing firms in Taiwan based on factor analysis and reported that value pricing is the most important factor, followed by consumer's price perception. The webpage is often one of the most important factors that determine whether the browsers will stay or not.

* Corresponding author. Tel.: +98 912536-7924

E-mail addresses: saho84@rocketmail.com (S. Hozouri)

C 2014 Growing Science Ltd. All rights reserved. doi: $10.5267 /$ j.uscm.2013.10.005 
Tang (2011) categorized the major purchasing helper from most websites and further gathered the common principles of layout at e-commerce webpage; the layout of buying helper. The common principles actually provided position-oriented characteristics, which could offer necessary guidelines for planning e-commerce webpage. Li (2005) presented a Web-enabled hybrid method for strategic marketing planning where it combines the group Delphi technique with a Web-based expert system, called WebStra (developed by the author), to support some key factors of the strategic marketing planning process.

Li (2005) reported that the approach was effective and efficient in terms of overcoming time and geographical barriers, saving decision-making time, coupling analysis with human judgment, helping consumers improve decision-making quality. Li and Li (2010) investigated some linking Web-based decision aid methods for international marketing planning and exploring the value of such integration. Li et al. (2011) presented a Web-based hybrid knowledge automation system, called WebDigital for analyzing digital marketing strategies and reported that the Web-enabled knowledge automation system could be an efficient and effective method for improving the digital marketing strategy formulation process and its output.

Azad et al. (2014a) performed an empirical investigation to detect important factors influencing information and communication technology (ICT) implementation in Iranian banking industry. The survey applied factor analysis to find important factors and reported six factors influencing ICT including efficiency approach, new advanced technological achievements, human resource management, service strategy, growth strategy and supporting systems. Azad et al. (2014b) performed another empirical investigation to detect important factors affecting customer relationship management (CRM) in an ICT firm based on factor analysis. The survey detected six factors influencing CRM learning performance attributes, enterprise resource planning, perception attributes, structure oriented, perception image and organizational resources.

\section{The proposed study}

In this paper, we study different factors influencing pricing strategy in food industry. The proposed study designs a questionnaire in Likert scale consists of 36 questions, distributes it among 311 Iranian experts in food industry and analyzes it based on principal component analysis. Cronbach alpha is calculated as 0.86 and Kaiser-Meyer-Olkin Measure of Sampling Adequacy and Approx. Chi-Square are 0.72 and 3614, respectively. Fig. 1 demonstrates the results of Scree plot. As we can observe from the results of Fig. 1, there are 11 factors, which could be extracted for further studies. Table 2 demonstrates the results of factor analysis on these factors.

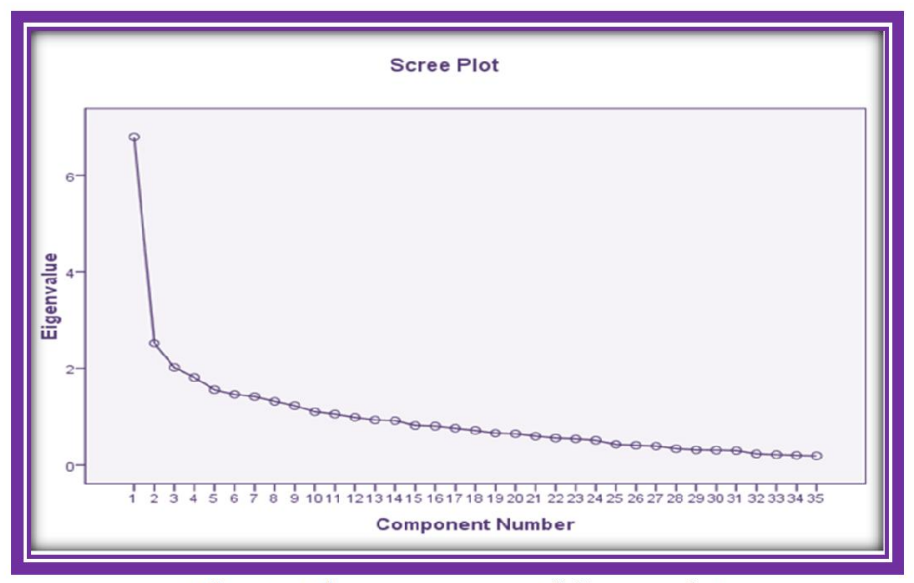

Fig. 1. The summary of Scree plot 
Table 1

The summary of principal component analysis after rotation

\begin{tabular}{|c|c|c|c|c|c|c|c|c|c|}
\hline & Total & $\begin{array}{c}\% \text { of } \\
\text { Variance }\end{array}$ & $\begin{array}{c}\text { Cumulative } \\
\%\end{array}$ & Total & $\begin{array}{c}\% \text { of } \\
\text { Variance }\end{array}$ & $\begin{array}{c}\text { Cumulative } \\
\%\end{array}$ & Total & $\%$ of Variance & Cumulative \% \\
\hline 1 & 6.796 & 19.418 & 19.418 & 6.796 & 19.418 & 19.418 & 2.575 & 7.356 & 7.356 \\
\hline 2 & 2.521 & 7.204 & 26.622 & 2.521 & 7.204 & 26.622 & 2.244 & 6.411 & 13.768 \\
\hline 3 & 2.019 & 5.770 & 32.392 & 2.019 & 5.770 & 32.392 & 2.189 & 6.253 & 20.021 \\
\hline 4 & 1.810 & 5.172 & 37.563 & 1.810 & 5.172 & 37.563 & 2.185 & 6.243 & 26.263 \\
\hline 5 & 1.559 & 4.455 & 42.018 & 1.559 & 4.455 & 42.018 & 2.080 & 5.942 & 32.205 \\
\hline 6 & 1.462 & 4.177 & 46.195 & 1.462 & 4.177 & 46.195 & 1.990 & 5.686 & 37.891 \\
\hline 7 & 1.416 & 4.045 & 50.241 & 1.416 & 4.045 & 50.241 & 1.967 & 5.621 & 43.512 \\
\hline 8 & 1.317 & 3.763 & 54.003 & 1.317 & 3.763 & 54.003 & 1.904 & 5.440 & 48.952 \\
\hline 9 & 1.227 & 3.506 & 57.509 & 1.227 & 3.506 & 57.509 & 1.776 & 5.075 & 54.027 \\
\hline 10 & 1.101 & 3.147 & 60.656 & 1.101 & 3.147 & 60.656 & 1.729 & 4.940 & 58.967 \\
\hline 11 & 1.053 & 3.009 & 63.665 & 1.053 & 3.009 & 63.665 & 1.644 & 4.698 & 63.665 \\
\hline 12 & .985 & 2.815 & 66.480 & & & & & & \\
\hline 13 & .931 & 2.659 & 69.139 & & & & & & \\
\hline 14 & .916 & 2.619 & 71.758 & & & & & & \\
\hline 15 & .816 & 2.331 & 74.089 & & & & & & \\
\hline 16 & .803 & 2.294 & 76.383 & & & & & & \\
\hline 17 & .759 & 2.170 & 78.553 & & & & & & \\
\hline 18 & .714 & 2.039 & 80.592 & & & & & & \\
\hline 19 & .658 & 1.880 & 82.473 & & & & & & \\
\hline 20 & .646 & 1.847 & 84.320 & & & & & & \\
\hline 21 & .595 & 1.701 & 86.021 & & & & & & \\
\hline 22 & .556 & 1.588 & 87.608 & & & & & & \\
\hline 23 & .538 & 1.536 & 89.145 & & & & & & \\
\hline 24 & .509 & 1.456 & 90.600 & & & & & & \\
\hline 25 & .425 & 1.215 & 91.815 & & & & & & \\
\hline 26 & .405 & 1.158 & 92.973 & & & & & & \\
\hline 27 & .389 & 1.112 & 94.085 & & & & & & \\
\hline 28 & .336 & .959 & 95.043 & & & & & & \\
\hline 29 & .310 & .886 & 95.929 & & & & & & \\
\hline 30 & .305 & .872 & 96.802 & & & & & & \\
\hline 31 & .295 & .843 & 97.644 & & & & & & \\
\hline 32 & .229 & .655 & 98.299 & & & & & & \\
\hline 33 & .212 & .605 & 98.904 & & & & & & \\
\hline 34 & .197 & .563 & 99.467 & & & & & & \\
\hline 35 & .186 & .533 & 100.000 & & & & & & \\
\hline
\end{tabular}

Based on the results of our survey, we have derived seven factors including supply management, environmental factors, product management, distribution structure, standardization strategies, market leadership and market organization. Next, we present details of our findings on testing the impact of various factors.

\section{The results}

In this section, we present details of our findings on seven influencing factors.

\subsection{The first factor: Environmental factors}

The first factor is associated with environmental factors. Table 2 demonstrates details of our study. As we can observe from the results of Table 2, "Investment in monopoly market in short term" is number one priority followed by "Market recession", "Amount of media advertisement", "Market activity with high level of political risk", "Currency fluctuation" and "Rules and regulations". 
Table 2

The summary of factors associated with environmental factors

\begin{tabular}{lccc}
\hline Option & Factor weight & P-Value & Results \\
\hline Investment in monopoly market in short term & 0.51 & $<0.001$ & Confirmed \\
Market recession & 0.50 & $<0.001$ & Confirmed \\
Amount of media advertisement & 0.041 & $<0.001$ & Confirmed \\
Market activity with high level of political risk & 0.36 & $<0.001$ & Confirmed \\
Currency fluctuation & 0.33 & $<0.001$ & Confirmed \\
Rules and regulations & 0.32 & $<0.001$ & Confirmed \\
\hline
\end{tabular}

\subsection{The second factor: Product management}

Product management is the second important issues and they include four factors, which are summarized in Table 3 as follows,

Table 3

The summary of factors associated with product management

\begin{tabular}{lccc}
\hline Option & Factor weight & P-Value & Results \\
\hline The level of technology used in products & 0.58 & $<0.001$ & Confirmed \\
Customer's needs & 0.38 & $<0.001$ & Confirmed \\
Innovation in products and services & 0.32 & $<0.001$ & Confirmed \\
Focus on related products & 0.36 & $<0.001$ & Confirmed \\
\hline
\end{tabular}

As we can observe from the results of Table 3, all four factors of "The level of technology used in products", "Customer's needs", "Focus on related products" and "Innovation in products and services" are having positive effect on pricing strategy.

\subsection{The third factor: Distribution management}

Distribution management is the third important issues and they include five factors, which are summarized in Table 4 as follows,

\section{Table 4}

The summary of factors associated with distribution management

\begin{tabular}{lccc}
\hline Option & Factor weight & P-Value & Results \\
\hline The conditions for negotiation & 0.58 & $<0.001$ & Confirmed \\
Competition among retailors & 0.36 & $<0.001$ & Confirmed \\
Demand for national brand & 0.34 & $<0.001$ & Confirmed \\
Offering products based on different cultures & 0.57 & $<0.001$ & Confirmed \\
Offering product through internet & - & $<0.074$ & Not confirmed \\
\hline
\end{tabular}

According to the results of Table 4, "The conditions for negotiation" is number one priority followed by "Offering product through internet", "Competition among retailors" and "Demand for national brand".

\subsection{The fourth factor: Standardization strategy}

Standardization strategy is the fourth important issues and they include three factors, presented in Table 5 as follows, 
Table 5

The summary of factors associated with standardization strategy

\begin{tabular}{lccc}
\hline Option & Factor weight & P-Value & Results \\
\hline Dynamics of market & 0.56 & $<0.001$ & Confirmed \\
Offering better services with no price change & 0.40 & $<0.001$ & Confirmed \\
Applying necessary standards on products and services & 0.30 & $<0.001$ & Confirmed \\
\hline
\end{tabular}

According to the results of Table 5, "Dynamics of market" is number one priority followed by "Offering better services with no price change" and "Applying necessary standards on products and services".

\subsection{The fifth factor: Distribution structure}

The structure of distribution channels is another factor with three sub-components, presented in Table 6 as follows,

\section{Table 6}

The summary of factors associated with distribution structure

\begin{tabular}{lccc}
\hline Option & Factor weight & P-Value & Results \\
\hline Life cycle of product & - & 0.10 & Not Confirmed \\
Product replacement & - & 0.887 & Not Confirmed \\
Speculation is raw materials & - & 0.061 & Not Confirmed \\
\hline
\end{tabular}

According to the results of Table 6, none of three factors is statistically significance and we can conclude that distribution structure has no impact on pricing strategy.

\subsection{The sixth factor: Market leadership}

Market leadership is the other factor with three sub-components, presented in Table 7 as follows,

Table 7

The summary of factors associated with market leadership

\begin{tabular}{lccc}
\hline Option & Factor weight & P-Value & Results \\
\hline Leadership in present market share & 0.60 & $<0.001$ & Confirmed \\
Paid wages & 0.50 & $<0.001$ & Confirmed \\
Leadership in price on the market & 0.24 & $<0.001$ & Confirmed \\
\hline
\end{tabular}

According to the results of Table 7, "Leadership in present market share" is number one priority followed by "Paid wages" and "Leadership in price on the market".

\subsection{The seventh factor: Market orientation}

The last factor is associated with market orientation with four factors presented in Table 8 as follows,

\section{Table 8}

The summary of factors associated with market orientation

\begin{tabular}{lccc}
\hline Option & Factor weight & P-Value & Results \\
\hline Integrated distribution channels & - & 0.296 & Not Confirmed \\
Handling distribution channels by firm itself & - & 0.180 & Not Confirmed \\
Clustering market based on customers & - & 0.679 & Not Confirmed \\
Having high quality products & - & 0.100 & Not Confirmed \\
\hline
\end{tabular}


According to the results of Table 6, none of four factors is statistically significance and we can conclude that market orientation has no impact on pricing strategy.

\section{Conclusion}

This paper has presented an investigation to detect important factors influencing pricing strategy. The proposed study of this paper has extracted five important factors including environmental, product management, distribution management, standardization strategy and market leadership. In terms of environmental factors, "Investment in monopoly market in short term" is number one priority followed by "Market recession", "Amount of media advertisement", "Market activity with high level of political risk", "Currency fluctuation" and "Rules and regulations". Product management is the second important issues where "The level of technology used in products", "Customer's needs", "Focus on related products" and "Innovation in products and services" are having positive effect on pricing strategy. The next factor, distribution management, includes different factors including "The conditions for negotiation" is number one priority followed by "Offering product through internet", "Competition among retailors" and "Demand for national brand". In terms of following good standards, "Dynamics of market" is number one priority followed by "Offering better services with no price change" and "Applying necessary standards on products and services". Finally, market leadership is the last item where "Leadership in present market share" is number one priority followed by "Paid wages" and "Leadership in price on the market".

\section{Acknowledgment}

The authors would like to thank the anonymous referees for their construction comments on earlier version of this work.

\section{References}

Azad, N., \& Hassanabadi, M. (2013). An empirical investigation on factors influencing on brand loyalty. Management Science Letters, 3(7), 2113-2118.

Azad, N., \& Mohammadi, M. (2013b). An empirical survey on factors influencing on packaging dairy products. Management Science Letters, 3(7), 1901-1906.

Azad, N., Nikanpour, M \& Hozouri, S. (2014a). An exploration study on influential factors on information and communication technology. Decision Science Letters, 3(1), 37-42.

Azad, N., Roshan, A \& Hozouri, S. (2014b). An exploration study on influential factors on customer relationship management. Decision Science Letters, 3(1), 49-56.

Li, S. (2005). A Web-enabled hybrid approach to strategic marketing planning: Group Delphi+ a Web-based expert system. Expert Systems with Applications, 29(2), 393-400.

Li, S., \& Li, J. Z. (2010). WebInternational: Combining Web-based knowledge automation, fuzzy rules and on-line databases for international marketing planning. Expert Systems with Applications, 37(10), 7094-7100.

Li, S., Zheng Li, J., He, H., Ward, P., \& Davies, B. J. (2011). WebDigital: A Web-based hybrid intelligent knowledge automation system for developing digital marketing strategies. Expert Systems with Applications,38(8), 10606-10613.

Mainela, T., \& Ulkuniemi, P. (2012). Personal interaction and customer relationship management in project business. Journal of Business \& Industrial Marketing, 28(2), 3-3.

Tang, J. (2011). A locality analysis on purchasing helper at e-commerce webpage-The example in TW, CN, MO and HK. Expert Systems with Applications, 38(1), 371-378.

Wang, Y. L., \& Tzeng, G. H. (2012). Brand marketing for creating brand value based on a MCDM model combining DEMATEL with ANP and VIKOR methods. Expert Systems with Applications, 39(5), 5600-5615. 